\title{
Prevalence and sources of stress among medical students in Universiti Sains Malaysia and Universiteit Maastricht.
}

\author{
Liew Yen Yee ${ }^{1}$, Muhamad Saiful Bahri Yusoff ${ }^{2}$ \\ ${ }^{1}$ Medical Student, ${ }^{2}$ Department of Medical Education, School of Medical Sciences, Universiti Sains Malaysia, \\ 16150 Kota Bharu, Kelantan, Malaysia.
}

\begin{tabular}{ll}
\hline ARTICLE INFO \\
Received & $: 10 / 06 / 2013$ \\
Accepted & $: 10 / 08 / 2013$ \\
Published & $: 01 / 12 / 2013$
\end{tabular}

\section{KEYWORD}

Psychological distress

Medical Students

Clinical

Pre-Clinical

Mental Health

\section{ABSTRACT}

Introduction: Various studies had been done on medical students stress, but there is yet no comparative study done between universities in Asia and Europe. Universiti Sains Malaysia (USM) and Universiteit Maastricht (UM) share a lot in common in terms of medical education as both actively apply PBL-oriented education into their curriculum. It will be interesting to find out the effect of differing culture, one Eastern and another Western, on the prevalence of stress and stressors among medical students of both universities. Method: A comparative study was conducted on medical students from USM and UM. Psychological distress was measured by the 12 item General Health Questionnaire and stressors were measured by the 40 item Medical Student Stressor Questionnaire. The calculated sample size was 215 per university. The collected data was analyzed using Statistical Package for Social Sciences (SPSS) version 20. Result: Results showed that the overall prevalence of psychological distress among medical students of USM and UM was $25.9 \%$ and no significant difference was found between the two universities. Binary logistic regression test showed that medical students in pre-clinical phase were 1.84 times more likely to develop psychological distress than medical students in clinical phases $(\mathrm{B}=0.612$, odd ratio $(\mathrm{CI} 95 \%)=1.84(1.16,2.93), \mathrm{p}=0.010)$. The major stressors were related to academic requirements, UM medical students perceived the stressors as causing less stress than USM medical students (t-stat (df) $=5.33$ (380), p-value $<0.001)$. Conclusion: Psychological health among medical students in the two universities was comparable. Academic requirements were the most stressful events as perceived by the students, but UM medical students had more positive perception toward the stressors than USM medical students. Pre-clinical students experienced higher psychological pressures than the clinical students. The medical schools should provide more attention to pre-clinical students because they might need psychological support from them.

(C) Medical Education Department, School of Medical Sciences, Universiti Sains Malaysia. All rights reserved.

CORRESPONDING AUTHOR: Dr Muhamad Saiful Bahri Yusoff, Medical Education Department, School of Medical Science, Universiti Sains Malaysia, Malaysia. Email: msaiful@kb.usm.my 


\section{Introduction}

The goal of medical education is to graduate knowledgeable, skillful, and professional physicians that will play an essential role in the society. Medical education have came a long way since Hippocrates and have evolved into a more organized and effective mechanism. However, some aspect of training may have produced some unintended negative stress on medical students' mental and emotional health. A recent multicenter study among first-year undergraduate medical students in four Malaysian universities reported an overall prevalence of stress is $50 \%$ at the end of year (1). While a study reported a prevalence of $21.9 \%$ to $36.5 \%$ across years of study at the beginning of year in a Malaysian medical school (2). Internationally the prevalence of psychological distress ranges from $21 \%$ to $62.7 \%$ across different phases of medical training (1-17).

Various stressors have been implicated as the possible cause of such distress. One of the major factors is academic and adjustment to medical school environment as a whole (2). Increased scholastic workload and concern for academic performance are among the recognized causes (2, 18). Besides that, interpersonal interactions between students and teachers can subtly but profoundly influence students (19). Medical students in the clinical years are confronted frequently with issues related to death and dying for the first time and they are reported to be often fearful, anxious, and hesitant to interact with dying patients (20). These stressors are unique to those in the health care field and medical student are often the ones who bore the brunt of the damage due to lack of preparedness.

On personal level, this stress may lead to substance abuse (21) or even suicide (22). On professional level, this stress may contribute to impaired academic performance $(23,24)^{10}$ and also to cynicism $(18,25)$ with decline in empathy and humanitarianism. Overall this may affect students' care of patients, relationship with faculty, and ultimately the culture of the medical profession.
Early detection of psychological condition is important to prevent psychological morbidity and its unwanted effects on medical students (18, 26, 27) and early detection is possible by determining the prevalence of stress among medical students. The next step of identifying of stressors of students can further pinpoint the source of the problem and assists in finding solutions.

Various studies regarding medical students stress had been done, but there is yet to be a comparative study done between universities in Asia and Europe. Universiti Sains Malaysia (USM) and Universiteit Maastricht (UM) share a lot in common in terms of medical education as both actively apply PBL-oriented education into their curriculum. It will be interesting to find out the effect of differing culture, one Eastern and another Western, on the stress prevalence and stressors among the medical students of both universities. The result of this study may prove invaluable to both universities for the mutual improvement in the name of medical education. This study aimed to answer five questions that include; 1) what are the prevalence of psychological distress among medical students of both universities? 2) What are the common stressors among medical students of both universities? 3) Is there any significant different of prevalence of psychological distress between the two universities? 4) Is there any significant different of perceived stressor by medical students between the two universities? 5) Is there any significant association between phases of medical training and psychological distress of both universities?

\section{Methodology}

\section{Study Design}

A comparative study was conducted in 2010 on medical students from medical faculties of two universities, USM and UM.

\section{Study Participants}

For the inclusion criteria, all pre-clinical and clinical year students (Year 1 to 5 in USM and Year 1 to 6 in UM) from medical faculties of the two universities were eligible to participate in 
this study. For the exclusion criteria, medical students who refused to participate and who were not reachable during the study.

\section{Sample Size Calculation}

The sample size was calculated by the sample size and power calculator (SPPC) using two proportions formula (28). The prevalence of psychological distress among medical students was approximately 30\% (2) and the general population was approximately $18 \%$ (29). Calculated sample size based on significant level of 0.05 and power of study of 0.80 was 195 per university. The adjusted sample size after $10 \%$ dropout rate was 215 per university.

\section{Sampling Method}

Due to the time constraint and availability of medical students at both universities during study period (i.e., about 6 weeks), purposive sampling method was applied. A total of 215 medical students across years of study at both universities were invited to participate in this study.

\section{Measurement tools}

Questionnaire, which consists of validated GHQ12 (30-33) and 40 item Medical Student Stressor Questionnaire (MSSQ-40) (34-37), were administered to the selected medical students. Both questionnaires were well validated among medical students. Relevant demographic profiles such as sex, years of study and university were collected by a structured demographic form. In USM, year 1 to 3 is pre-clinical year and year 4 to 5 is clinical year. In UM, year 1 to 3 is preclinical and year 4 to 6 is clinical year. GHQ scores more than 3 was considered as psychological distress (30-33). Mean scores for MSSQ domains and items were categorized into causing none to mild stress (0 to 1 ), causing mild to moderate stress (1.01 to 2), causing moderate to high (2.01 to 3) and causing high to severe stress (3.01 to 4) (34-37).

\section{Data Collection}

Ethical clearance was obtained from the Human Ethical Committee USM and permission was sought from UM prior to study begin. All participants were given information about the study, verbal and signed consents were taken from them. The guided self-administered questionnaire was done to collect the data. Data was collected within 6 weeks.

\section{Statistical Analysis}

The collected data was analyzed using Statistical Package for Social Sciences (SPSS) version 20. Descriptive analysis was performed to report demographic profile. Chi-square test was performed to test different between factors and categorical outcomes. Independent-t test was performance to test different between factors and continuous outcomes. Binary logistic regression was performed to estimate odd ratio. Assumptions of each statistical was checked prior to analysis.

\section{Result}

Table 1: Demographic profiles of medical students by university

\begin{tabular}{|c|c|c|}
\hline Variable & USM & UM \\
\hline \multicolumn{3}{|l|}{ Sex, n (\%) } \\
\hline Male & $071(34.6)$ & $084(47.5)$ \\
\hline Female & $134(65.4)$ & $093(52.5)$ \\
\hline Total & $205(100)$ & $177(100)$ \\
\hline \multicolumn{3}{|l|}{ Phase of training, n (\%) } \\
\hline Pre-clinical & $095(46.3)$ & $082(46.3)$ \\
\hline Clinical & $110(53.7)$ & 095 (53.7) \\
\hline Total & 205 (100) & $177(100)$ \\
\hline \multicolumn{3}{|c|}{$\begin{array}{l}\text { Psychological health status, n } \\
(\%)^{\mathrm{a}}\end{array}$} \\
\hline Non-distress & $145(70.7)$ & $138(78.0)$ \\
\hline Distress & 060 (29.3) & $039(22.0)$ \\
\hline Total & 205 (100) & $177(100)$ \\
\hline \multicolumn{3}{|l|}{ Stressor, mean (SD) ${ }^{\mathbf{b}}$} \\
\hline Academic** & $1.99(0.82)$ & $1.57(0.71)$ \\
\hline Inter- \& intrapersonal & $0.97(0.92)$ & 1.08 (0.89) \\
\hline Teaching \& Learning & $1.19(0.90)$ & $1.07(0.76)$ \\
\hline Social* & $0.87(0.68)$ & $1.06(0.61)$ \\
\hline Drive \& Desire & $0.66(0.82)$ & $0.66(0.68)$ \\
\hline Group activities** & $1.49(0.95)$ & $1.07(0.78)$ \\
\hline \multicolumn{3}{|c|}{$\begin{array}{l}{ }^{a} \text { Chi-square test was performance, } \mathrm{p} \text {-value less than } 0.05 \text { was } \\
\text { considered as significant difference. }{ }^{\mathrm{b}} \text { Independent-t test was } \\
\text { performance, p-value less than } 0.05 \text { was considered as } \\
\text { significant difference; SD }=\text { standard deviation; }{ }^{* *} \text { p-value }< \\
0.001,{ }^{*} \text { p-value }<0.01\end{array}$} \\
\hline
\end{tabular}

A total of 382 medical students participated in this study; 205 USM and 177 UM medical students (Table 1). 
The overall prevalence of psychological distress among the medical students was $25.9 \%$ (i.e. 99 out of 382 medical students). Specifically, the prevalence among USM medical students (29.3\%) was higher than UM medical students (22\%) (Table 1), however no significant difference was found $\left(\mathrm{X}^{2}(\mathrm{df})=2.59(1), \mathrm{p}=\right.$ 0.108).

Three stressors were significantly difference between the two universities; academic ( $\mathrm{t}$-stat (df) $=5.33$ (380), p-value < 0.001), social (t-stat $(\mathrm{df})=-2.87(380)$, p-value $=0.004)$, and group activities (t-stat (df) $=4.71$ (380), p-value < 0.001 ) as shown in table 1 . In other hand three stress were not significantly difference between the two universities; inter- \& intrapersonal (t-stat $(\mathrm{df})=-1.18$ (380), p-value $=0.234)$, teaching $\&$ learning (t-stat $(\mathrm{df})=1.34$ (380), $\mathrm{p}$-value $=$ 0.182 ), and drive \& desire ( $\mathrm{t}$-stat $(\mathrm{df})=--0.02$ (380), $\mathrm{p}$-value $=0.986$ ) as shown in table 1 .

Table 2: Association of psychological distress with phase of medical training

\begin{tabular}{lcccc}
\hline \multirow{2}{*}{ Variable } & $\begin{array}{c}\text { Psychological distress, } \\
\text { n (\%) }\end{array}$ & $\begin{array}{c}\boldsymbol{X}^{2}- \\
\text { statistic } \\
\text { s (df) }\end{array}$ & $\begin{array}{l}\text { p- } \\
\text { value }\end{array}$ \\
\cline { 2 - 3 } & Yes & No & & \\
\hline $\begin{array}{l}\text { Phase of } \\
\text { training }\end{array}$ & & & & \\
$\quad \begin{array}{l}\text { Pre-clinical } \\
\text { Clinical }\end{array}$ & $57(32.2)$ & $120(67.8)$ & $6.79(1)$ & 0.009 \\
$\begin{array}{l}\text { Pre-clinical } \\
\text { phase }\end{array}$ & $42(20.5)$ & $163(79.5)$ & & \\
$\quad$ USM & $35(36.8)$ & $60(63.2)$ & & \\
$\quad$ UM & $22(26.8)$ & $60(73.2)$ & & \\
$\begin{array}{l}\text { Clinical } \\
\text { phase }\end{array}$ & & & & \\
$\quad$ USM & $25(22.7)$ & $85(77.3)$ & 0.155 \\
$\quad$ UM & $17(17.9)$ & $78(82.1)$ & $0.73(1)$ & 0.393 \\
\hline
\end{tabular}

Chi-square test was performed to test association between phase of medical training and psychological distress status. Results showed that the phase of medical training was significantly associated with psychological distress (Table 2). The percentage of psychological distress was significantly higher in the pre-clinical phase $(32.2 \%)$ than the clinical phase (20.5\%). Subgroup analysis within each phase of medical training, it appeared that psychological distress was more prevalent among USM medical students than UM medical students, however no significant different was found (Table 2)

Binary logistic regression test showed that medical students in pre-clinical phase were 1.84 times more likely to develop psychological distress than medical students in clinical phases $(\mathrm{B}=0.612$, odd ratio $(\mathrm{CI} 95 \%)=1.84$ (1.16, 2.93), $\mathrm{p}=0.010$; model summary, $X^{2}=6.79,-2$ Log likelihood 430.4, $\mathrm{p}=0.009$; university and sex were included in the analysis and showed no significant results).

Subgroup analysis of stressor between the two universities was performed and summarised in table 3. The analysis showed that only one stressor was perceived as causing moderate to high stress by UM medical students (i.e., examinations), however it is significantly lower than USM medical students. Five stressors (i.e., examinations, large amount of contents to be studied, lack of time to review what have learnt, not enough medical skills, and need to well due to self-expectation) were perceived as causing moderate to high stress by USM medical students. Overall, UM medical students had more positive perception towards stressors compared to the USM medical students except for social related stressors.

In summary, the results showed that the overall prevalence of psychological distress among medical students of USM and UM was 25.9\% and no significant difference was found between the two universities. Interestingly, medical students in clinical phase had better psychological health than those in pre-clinical phase. As expected, the major stressors were related to academic requirements. It appeared that UM medical student had more positive perception towards most of the stressors compared to USM medical students. 
Table 3: Stressors that were perceived significantly different by USM and UM medical students

\begin{tabular}{|c|c|c|c|c|}
\hline \multirow{2}{*}{ Stressor } & \multicolumn{2}{|c|}{ Perceived stress, mean (SD) } & \multirow{2}{*}{ t- statistics (df) } & \multirow{2}{*}{ p-value } \\
\hline & USM & UM & & \\
\hline \multicolumn{5}{|l|}{ Academic } \\
\hline Examinations & $2.77(0.99)$ & $2.06(1.00)$ & $6.93(380)$ & $<0.001$ \\
\hline Large amount of contents to be learnt & $2.42(1.09)$ & $1.80(1.06)$ & $5.64(380)$ & $<0.001$ \\
\hline Lack of time to review what have learnt & $2.34(1.12)$ & $1.63(1.04)$ & $6.43(380)$ & $<0.001$ \\
\hline Not enough medical skill practice & $2.16(1.10)$ & $1.59(1.11)$ & $5.02(380)$ & $<0.001$ \\
\hline Need to do well (self-expectation) & $2.04(1.16)$ & $1.79(1.21)$ & $2.08(380)$ & 0.038 \\
\hline Heavy workload & $1.99(1.10)$ & $1.64(0.97)$ & $3.19(380)$ & 0.002 \\
\hline Unable to answer the questions from teachers & $1.99(1.19)$ & $1.44(1.12)$ & $4.59(380)$ & $<0.001$ \\
\hline Falling behind in reading schedule & $1.94(1.16)$ & $1.36(0.94)$ & $5.33(380)$ & $<0.001$ \\
\hline $\begin{array}{l}\text { Having difficulty in understanding the } \\
\text { content }\end{array}$ & $1.90(1.12)$ & $1.42(1.05)$ & $4.29(380)$ & $<0.001$ \\
\hline Quota system in examinations & $1.56(1.27)$ & $0.95(1.04)$ & $5.05(380)$ & $<0.001$ \\
\hline Learning context full of competition & $1.56(1.15)$ & $1.25(1.03)$ & $2.72(380)$ & 0.007 \\
\hline \multicolumn{5}{|l|}{ Inter- \& intrapersonal } \\
\hline Poor motivation to learn & $1.43(1.31)$ & $1.14(1.07)$ & $2.37(380)$ & 0.018 \\
\hline Verbal or physical abuse by teachers & $0.98(1.28)$ & $1.08(1.21)$ & $-2.34(380)$ & 0.020 \\
\hline Conflicts with teachers & $0.82(1.20)$ & $1.24(1.13)$ & $-3.43(380)$ & 0.001 \\
\hline Conflicts with personnel & $0.75(1.15)$ & $1.02(1.16)$ & $-1.99(380)$ & 0.047 \\
\hline \multicolumn{5}{|l|}{ Teaching \& Learning } \\
\hline Lack of guidance from teachers & $1.29(1.23)$ & $0.89(0.99)$ & $3.42(380)$ & 0.001 \\
\hline Teachers lack of teaching skills & $1.23(1.23)$ & $0.97(0.92)$ & $2.29(380)$ & 0.023 \\
\hline Not enough study material & $1.19(1.14)$ & $0.95(1.03)$ & $2.06(380)$ & 0.040 \\
\hline \multicolumn{5}{|l|}{ Social } \\
\hline Lack of time for family and friends & $1.20(1.21)$ & $1.50(1.02)$ & $-2.62(380)$ & 0.009 \\
\hline Unable to answer questions from patients & $1.09(1.12)$ & $1.42(1.06)$ & $-3.00(380)$ & 0.003 \\
\hline Facing illness or death of the patients & $0.94(1.04)$ & $1.40(1.11)$ & $-4.15(380)$ & $<0.001$ \\
\hline Talking to patients about personal problems & $0.45(0.85)$ & $0.76(0.86)$ & $-3.53(380)$ & $<0.001$ \\
\hline \multicolumn{5}{|l|}{ Drive \& Desire } \\
\hline Parental wish for you to study medicine & $0.58(0.98)$ & $0.39(0.83)$ & $2.03(380)$ & 0.043 \\
\hline \multicolumn{5}{|l|}{ Group activities } \\
\hline Need to do well (imposed by others) & $1.58(1.18)$ & $1.25(1.09)$ & $2.85(380)$ & 0.005 \\
\hline Participation in class presentation & $1.54(1.14)$ & $1.07(1.04)$ & $4.12(380)$ & $<0.001$ \\
\hline Feeling of incompetence & $1.48(1.19)$ & $1.21(1.16)$ & $2.18(380)$ & 0.030 \\
\hline Participation in class discussion & $1.37(1.20)$ & $0.74(0.92)$ & $5.67(380)$ & $<0.001$ \\
\hline
\end{tabular}

\section{Discussion}

Our study found that the prevalence of psychological distress among medical students of both USM and UM was $25.9 \%$. This finding is in line with literature reported that the overall prevalence ranges from $21 \%$ to $62.7 \%$ across different phases of medical training (1-17); in fact it is at the low side. We found that the prevalence of psychological distress among UM medical students was $22 \%$ and among USM medical students was 29.3\%; it seems that UM medical students had less prevalence compared to USM medical students, however no significant difference was found. This finding suggested that psychological health among medical students in UM and USM was comparable as well as with findings reported in the literature (1-17). Conversely, the prevalence is still higher than the prevalence of general population, less than $18 \%$ (29), as well as prevalence of prospective medical students, less than 3\% $(4,38)$. Despite 
considerably low prevalence found in this study, yet active and preventive measures should be brought in by medical schools at earliest possible because early intervention could buffer the unwanted consequences of psychological distress on medical students' personal and professional development (18, 26, 27).

Interestingly, we found that medical students in the clinical years experienced less psychological distress compared to medical students in the preclinical years. In facts, analysis showed that those in pre-clinical were 1.8 times more likely to develop psychological distress than those in clinical years. At the beginning, we anticipated that those in clinical years would experience more psychological pressures than those in preclinical years because logically the commitment and workload would be heavier in the clinical years compared to the pre-clinical years. However, this finding is consistent with a previous study reported that medical students in clinical years demonstrated less psychological pressure than the pre-clinical years (2). One possible reason for the low psychological distress in clinical year students is that they have developed skills to manage their studies and therefore are better able to cope with stress, in comparison to students in pre-clinical years (2). One important lesson learnt is that more attention should be given to the pre-clinical medical students due to they are at a transitional period for adjustment with the demanding medical training environment thus they might need psychological support from medical schools. Medical schools could introduce a stress reduction intervention to help them to deal with the demanding environment $(18,26,27)$. This study found no significant relationship between sex and psychological distress; therefore signify male and female students were equally vulnerable to develop psychological distress.

As we anticipated, the major stressors for both universities were related to academic requirements (table 1 and table 3 ) and this is consistent with previous findings $(1,2,18,39$, 40). Likewise, our findings support findings from previous studies reported that regardless of medical education setups, the main stressors would be similar but the frequency might be different (39, 40). Results demonstrated USM medical students perceived academic requirements as causing significantly more stress than the UM medical students. In other word, the UM medical students had healthier perception or mindset about the academic requirements than the USM medical students. It is worthy to highlight, medical students who perceived academic requirement as causing unfavourable stress are 16 times more risk to develop psychological distress compared to those who perceived it as causing favourable stress (1). One important lesson learnt is that a curriculum should be designed in a way that could optimize the balance between the 'push' factors (bringing out the best in students and maintaining standards) and induction of unnecessary psychological pressure (1). Perhaps, a challenging task for medical educators is to come out with a psychological-friendly medical curriculum to remedy this chronic situation. Training medical students to have healthy mindset towards academic requirements as well as other stressors might help them to deal with the demanding medical training environment $(26,27)$.

This study has several limitations which need to be considered in the future. The first limitation was related to the sample size due to inadequate samples of UM medical students therefore the comparison might not reflect the true different between the two universities. The second was related to non-probability sampling method employed in this study that may lead to bias in selection of study subjects therefore may result in inaccurate results. The third was related to the study design which may not reflect the real pattern of psychological distress in the study population due to cross-sectional in nature, thus limiting its generalisability to different time intervals. The last limitation was the study population involved only from two educational settings, which the results may not be generalized to other educational settings. Considering all these limitations the results of this study should be interpreted cautiously. 


\section{Conclusion}

Psychological health among medical students in the two universities was comparable. Academic requirements were the most stressful events as perceived by the students, but UM medical students had more positive perception toward the stressors than USM medical students. Preclinical students experienced higher psychological pressures than the clinical students. The medical schools should provide more attention to pre-clinical students because they might need psychological support from them.

\section{Acknowledgement}

Our special thanks to the School of Medical Sciences, Universiti Sains Malaysia and Universiteit Maastricht for supporting and allowing us undertook this study. Our appreciation to all medical students who involved in this study. Our special thank you also to Professor Dr Job Metsemakers, Maastricht University for his support during data collection.

\section{Reference}

1. Yusoff MSB, Liew YY, Ling HW, Tan CS, Loke HM, Lim XB, et al. A study on stress, stressors and coping strategies among Malaysian medical students. International Journal of Students’ Research. 2011;1(2):4550.

2. Yusoff MSB, Rahim AFA, Yaacob MJ. Prevalence and sources of stress among Universiti Sains Malaysia Medical Students. Malaysian Journal of Medical Sciences. 2010;17(1):30-7.

3. Aktekin M, Karaman T, Senol YY, Erdem S, Erengin H, Akaydin M. Anxiety, depression and stressful life events among medical students: a prospective study in Antalya, Turkey. Medical education. 2001;35(1):127.

4. Yusoff MSB, Abdul Rahim AF, Baba AA, Ismail SB, Mat Pa MN, Esa AR. The impact of medical education on psychological health of students: A cohort study. Psychology, Health \& Medicine [serial on the Internet]. 2012.

5. Yusoff MSB, Rahim AFA, Yaacob MJ. The prevalence of final year medical students with depressive symptoms and its contributing factors. International Medical Journal. 2011;18(4):305-9.

6. Johari A, Hashim IN. Stress and coping strategies among medical students in National University of Malaysia, Malaysia University of Sabah and University Kuala Lumpur Royal College of Medicine Perak. Journal of Community Health. 2009;15(2):106-15.

7. Zaid Z, Chan S, Ho J. Emotional disorders among medical students in a Malaysian private medical school. Singapore medical journal. 2007;48(10):895-9.

8. Chandrasekhar TS, Pathiyil RS, Binu VS, Chiranjoy M, Biswabina R, Ritesh GM. Psychological morbidity, sources of stress and coping strategies among undergraduate medical students of Nepal. BMC Medical education. 2007;7(1):26.

9. Dahlin M, Joneborg N, Runeson B. Stress and depression among medical students: A cross-sectional study. Medical education. 2005;39(6):594-604.

10. Saipanish R. Stress among medical students in a Thai medical school. Medical teacher. 2003;25(5):502-6.

11. Mohd Sidik S, Rampal L, Kaneson N. Prevalence of emotional disorders among medical students in a Malaysian university. Asia Pacific Family Medicine. 2003;2(4):213-7.

12. Mohd Sidik S, Kaneson N. The prevalence of depression among medical students. Malaysian Journal of Psychiatry. 2003;11(1):12-7.

13. Ko S, Kua E, Fones C. Stress and the undergraduates. Singapore medical journal. 1999;40(10):627-30.

14. Guthrie EA, Black D, Bagalkote H, Shaw C, Campbell M, Creed F. Psychological stress and burnout in medical students: a five-year prospective longitudinal study. Journal of the Royal Society of Medicine. 1998;91(5):237-43.

15. Guthrie EA, Black D, Shaw CM, Hamilton J, Creed FH, Tomenson B. Embarking upon a medical career: psychological morbidity in first year medical students. Medical education. 1995;29(5):337-41.

16. Vitaliano PP, Maiuro RD, Russo J, Mitchell ES. Medical student distress: A longitudinal study. Journal of Nervous and Mental Disease. 1989;177(2):70-6.

17. Firth J. Levels and sources of stress in medical students. British medical journal 
(Clinicalresearch ed). 1986;292(6529):117780.

18. Dyrbye LN, Thomas MR, Shanafelt TD. Medical student distress: causes, consequences, and proposed solutions. Mayo Clinic Proc. 2005;80(12):1613-22.

19. Hafferty FW. Beyond curriculum reform: confronting medicine's hidden curriculum. Academic Medicine. 1998;73(4):403-7.

20. Binienda J, Schwartz K, Gaspar D. Training in end-of-life care through interaction with dying patients. Academic Medicine. 2001;76(5):517.

21. Croen LG, Woesner M, Herman M, Reichgott M. A longitudinal study of substance use and abuse in a single class of medical students. Academic Medicine. 1997;72(5):376-81.

22. Pepitone-Arreola-Rockwell F, Rockwell D, Core N. Fifty-two medical student suicides. The American journal of psychiatry. 1981;138(2):198.

23. Grover PL, Smith DU. Academic anxiety, locus of control, and achievement in medical school.Academic Medicine. 1981;56(9):72736.

24. Yusoff MSB. Associations of pass-fail outcomes with psychological health of first year medical students in a Malaysian medical school. SQU Med J Oman. 2013;13(1):108-16.

25. Crandall SJ, Volk RJ, Loemker V. Medical students' attitudes toward providing care for the underserved. JAMA: the journal of the American Medical Association. 1993;269(19):2519-23.

26. Yusoff MSB, Esa AR. Stress management for medical students: A systematic review. In: Lopez-Varela MA, editor. Social Sciences and Cultural Studies - Issues of Language, Public Opinion, Education and Welfare. Croatia: InTech; 2012.

27. Shapiro SL, Shapiro DE, Schwartz GER. Stress management in medical education: a review of the literature. Academic Medicine. 2000;75(7):748.

28. Barman A. Sample Size Precision and Power Calculator. 1.0 ed. Malaysia: Arunodaya Barman; 2009.

29. Nordin NM, Talib MA, Yaacob SN. Personality, loneliness and mental health among undergraduates at Malaysian Universities. European Journal of Scientific Research. 2009;36(2):285-98.

30. Yusoff MSB, Rahim AFA, Yaacob M. The sensitivity, specificity and reliability of the Malay version 12-items General Health
Questionnaire (GHQ-12) in detecting distressed medical students. ASEAN Journal of Psychiatry. 2010;11(1).

31. Yusoff MSB. The validity of two Malay versions of the general health questionnaire (GHQ) in detecting distressed medical students ASEAN Journal of Psychiatry. 2010;11(2):1-8.

32. Goldberg DP, Gater R, Sartorius N, Ustun T, Piccinelli M, Gureje $\mathrm{O}$, et al. The validity of two versions of the GHQ in the WHO study of mental illness in general health care. Psychological Medicine. 1997;27(1):191-7.

33. Goldberg D. Manual of the General Health Questionnaire. Windsor. Berks:: NFER Publishing Company; 1978.

34. Yusoff MSB, Rahim AFA, Yaacob MJ. The development and validity of the Medical Student Stressor Questionnaire (MSSQ). Asean Journal of Psychiatry. 2010;11(1):231-5.

35. Yusoff MSB, Rahim AFA. The manual of Medical Student Stressor Questionnaire (MSSQ). Malaysia: KKMED Publications; 2010. Available from: http://www.medic.usm.my/dme/images/stori es/staff/KKMED/2010/manual\%20usmeqi.pdf.

36. Yusoff MSB. A Confirmatory Factor Analysis Study on the Medical Student Stressor Questionnaire among Malaysian medical students. Education in Medicine Journal. 2011;3(1):e44-e55.

37. Yusoff MSB. A multicenter study on validity of the Medical Student Stressor Questionnaire (MSSQ). International Medical Journal. 2011;18(1):14-8.

38. Smith CK, Peterson DF, Degenhardt BF, Johnson JC. Depression, anxiety, and perceived hassles among entering medical students. Psychology, health \& medicine. 2007;12(1):31-9.

39. Kaufman DM, Mensink D, Day V. Stressors in Medical School: Relation to curriculum format and year of study. Teaching and Learning in Medicine. 1998;10(3):138-44.

40. Kaufman DM, Day V, Mensink D. Stressors in 1st-Year Medical School: Comparison of a Conventional and Problem-Based Curriculum. Teaching and Learning in Medicine: An International Journal. 1996;8(4):188-94. 